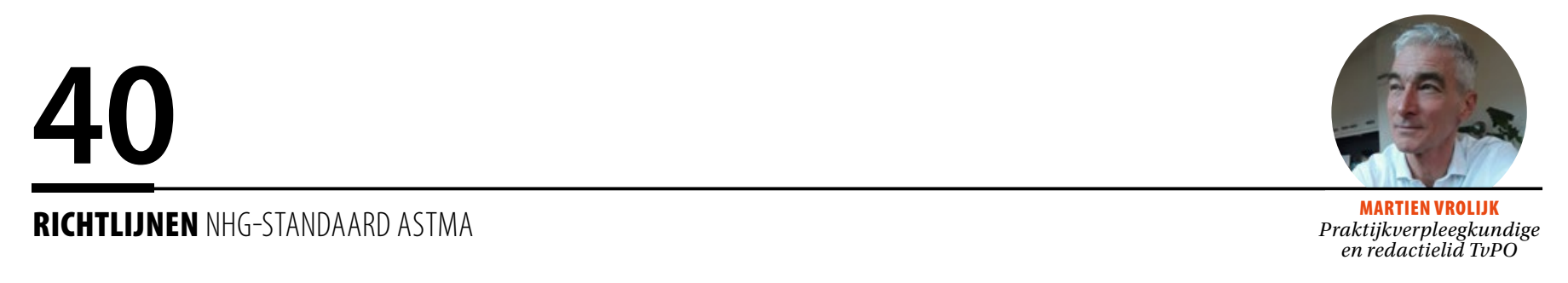

\title{
Astma bij volwassenen
}

De NHG-Standaard Astma bij volwassenen, nu na vijf jaar weer herzien, geeft richtlijnen voor de diagnostiek, behandeling en monitoring van astma bij patiënten vanaf achttien jaar. Naast achtergrondinformatie worden in dit artikel de belangrijkste wijzigingen en kernboodschappen genoemd.

\begin{abstract}
Astma begint meestal op de jonge kinderleeftijd, maar kan ook na het vijftigste jaar voor het eerst optreden. Het aantal gevallen (prevalentie) in de huisartsenpraktijk is 107 per 1000 . De incidentie is ongeveer 6 per 1000 patiënten per jaar. Astma vermindert nauwelijks de levensverwachting. Naast genetische factoren zijn bij het ontwikkelen van astma sensibilisatie voor allergische prikkels door inhalatie of aanwezigheid in de voeding van belang, zoals huisstofmijt, huisdieren, schimmels, pollen, melk, soja, pinda's of noten en beroepsmatig contact met allergenen. Ook kan blootstelling aan niet-allergische prikkels zoals virale infecties, rook, fijnstof, stress, kou, mist, bepaalde geneesmiddelen en dergelijke klachten uitlokken.
\end{abstract}

\section{Overmatig SABA-gebruik}

In de afgelopen jaren is duidelijker geworden dat er schadelijke effecten zijn van overmatig gebruik

\section{Kernboodschappen \\ - De diagnose astma wordt gesteld op basis van anamnese, lichamelijk onderzoek en spirometrie. Niet roken en een rookvrije omgeving zijn de belangrijkste niet-medicamenteuze maatregelen. \\ - Inhalatiecorticosteroïden (ICS), al dan niet in combinatie met langwerkende bèta-2-mimetica (LABA), zijn de hoeksteen van de medicamenteuze behandeling van astma en worden niet gestart voordat de diagnose astma voldoende zeker is gesteld. \\ - Bij goede astmacontrole is SABA-gebruik vrijwel niet nodig, (overmatig) SABA-gebruik > 2/week is een teken van onvoldoende astmacontrole.}

(vaker dan twee keer per week) van een kortwerkend bèta-2-mimeticum (SABA). Overmatig SABAgebruik is meestal een teken van onvoldoende astmacontrole. Patiënten die frequent een SABA gebruiken zonder onderhoudsbehandeling met ICS, hebben een hoger risico op longaanvallen (exacerbaties), ziekenhuisopname en overlijden. Het indicatiegebied voor gebruik van een SABA is daarom beperkter geworden en preventie van overmatig SABA-gebruik is toegevoegd.

Nieuw is de mogelijkheid om bij een duidelijke astmadiagnose de eerste medicatiestap over te slaan en laagdrempelig te starten met een ICS-onderhoudsbehandeling om zo een betere astmacontrole te bereiken.

\section{Anamnese en diagnostiek}

Bij de anamnese wordt aandacht besteed aan kortademigheid, al dan niet in combinatie met piepen; frequentie, duur (incidenteel, aanvalsgewijs, regelmatig, dagelijks), nachtelijke klachten en hoesten. Daarnaast is van belang te onderzoeken of er aanwijzingen zijn voor allergische en niet-allergische prikkels, wordt het roken besproken, de invloed op het dagelijks functioneren thuis of elders (ziekteverzuim) en preventieve maatregelen die de patiënt heeft getroffen, en het effect daarvan wordt aangekaart. Vervolgens is naast de voorgeschiedenis aandacht voor werkgerelateerde klachten. Bij het lichamelijk onderzoek wordt de mate van dyspnoe en hartfrequentie bepaald, en eventueel bij aanwezige dyspnoe de saturatie. Bij verpleegkundigen die de vaardigheid van longauscultatie bezitten, wordt 


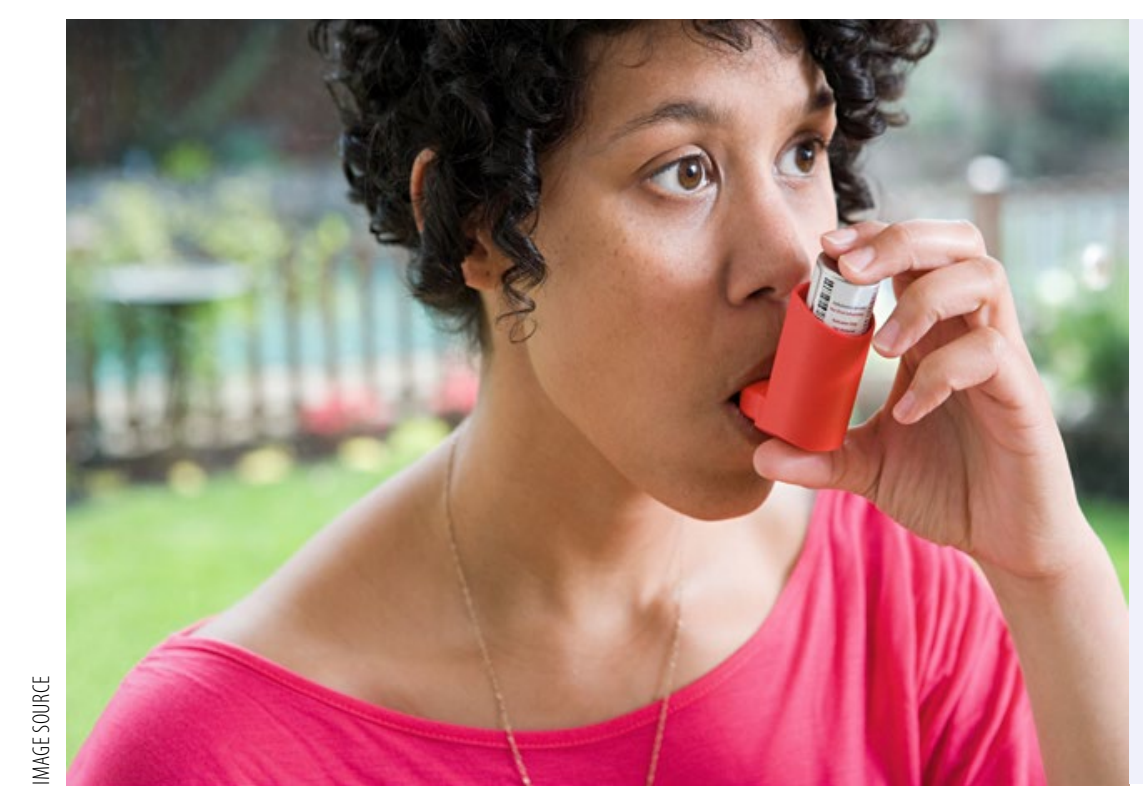

\section{Belangrijkste wijzigingen}

\author{
- De diagnostische criteria zijn aangescherpt. \\ - Het indicatiegebied voor gebruik van een kortwerkend \\ bèta-2-mimeticum (SABA) is beperkter geworden. \\ - Beleid bij overmatig SABA-gebruik is toegevoegd. \\ - Bij het stappenplan is de optie om stap 1 over te slaan \\ toegevoegd. \\ - De mogelijkheid om bij stap 2 formoterol-ICS voor \\ gebruik zo nodig te geven is aan het stappenplan \\ toegevoegd. \\ - De informatie over medicatiegebruik bij zwangerschap \\ en borstvoeding is aangevuld. \\ - Inhalatiemedicatie wordt weergegeven in een lage, een \\ intermediaire en een hoge dosering. \\ - Het beleid bij een longaanval is geactualiseerd.
}

gelet op de aanwezigheid van een verlengd expirium en/of expiratoir piepen. Bij grove/fijne crepitaties is zonder meer overleg met de arts geïndiceerd.

NB: Om de diagnose astma te kunnen stellen zijn vaak meerdere consulten nodig, waarbij er een belangrijke protocollaire rol is weggelegd voor de praktijkverpleegkundige/-ondersteuner.

\section{Aanvullend onderzoek}

Spirometrie wordt verricht bij het vermoeden van astma, bij voorkeur ten tijde van klachten. Het doel van spirometrie is aanwijzingen voor restrictie na te gaan c.q. uit te sluiten, obstructie aan te tonen, de ernst van de obstructie te bepalen en de mate van reversibiliteit te bepalen. De diagnostische criteria zijn aangescherpt om zo onder- en overdiagnose en daarmee ook onder- of overbehandeling te voorkomen.

Spirometrisch aangetoonde reversibiliteit of variabiliteit (FEV1 verschil van $12 \%$ en $200 \mathrm{ml}$ tussen twee metingen) is obligaat voor de diagnose. Overweeg bij blijvende onzekerheid over de diagnose astma (klachten zonder aangetoonde reversibele of variabele luchtwegobstructie) een histamine- of metacholineprovocatietest. Een X-thorax is bij (verdenking van) astma niet geïndiceerd, behalve als benauwdheidsklachten niet te verklaren zijn door de astma. Bij patiënten met (aanwijzingen voor) astma wordt een screeningstest verricht op inhalatieallergenen in het bloed als aanwijzingen voor allergische oorzaken anamnestisch onduidelijk zijn. Dit geldt ook bij onvoldoende astmacontrole ondanks medicatie. Onderzoek naar sensibilisatie van voedselallergenen heeft geen toegevoegde waarde omdat bij een positief s IgE nog niet bewezen is dat er een verband bestaat met de symptomen. Anderzijds kan men aan een voedselallergie lijden zonder aantoonbare sensibilisatie - zie de NHG-Standaard Voedselovergevoeligheid.

NB: In verband met COVID-19 wordt ten aanzien van spirometrie geadviseerd de leidraden van de CaHAG te volgen, zie https://corona.nhg.org/richtlijnen-leidraden-en-standpunten/.

\section{Behandeldoelen}

Het doel van de behandeling van volwassenen met astma is het minimaliseren van klachten, het risico op longaanvallen, beperking in functioneren, persisterende luchtwegobstructie, mortaliteit en bijwerkingen van medicatie. Het bereiken van een goede astmacontrole wordt afgestemd op de persoonlijke behandeldoelen van de patiënt. Goede astmacontrole is niet altijd haalbaar. Bij blijvend onvoldoende astmacontrole worden afspraken gemaakt over haalbare (persoonlijke) behandeldoelen. De door de patiënt ervaren klachten en de manier waarop de patiënt hiermee omgaat, staan bij de behandeling centraal. 


\section{Stappenplan inhalatiemedicatie astma bij volwassenen}

\begin{tabular}{|l|l|l|l|l|}
\hline & $\begin{array}{l}\text { Stap 1 (optioneel) } \\
\text { SABA of ICS-formoterol zo nodig }\end{array}$ & $\begin{array}{l}\text { Stap 2 } \\
\text { ICS }\end{array}$ & $\begin{array}{l}\text { Stap 3 } \\
\text { Lage dosis ICS/LABA }\end{array}$ & $\begin{array}{l}\text { Stap } 4 \\
\text { Intermediaire tot hogere dosis ICS/LABA }\end{array}$ \\
\hline $\begin{array}{l}\text { (onderhouds) } \\
\text { behandeling }\end{array}$ & $\begin{array}{l}\text { Alleen SABA zo nodig* of lage } \\
\text { dosis ICS-formoterol zo nodig* bij } \\
\text { klachten, of meteen stap 2 }\end{array}$ & $\begin{array}{l}\text { Lage dosis ICS of lage } \\
\text { dosis ICS-formoterol zo } \\
\text { nodig bij klachten* }\end{array}$ & $\begin{array}{l}\text { Lage dosis ICS+LABA of } \\
\text { intermediaire dosis ICS } \\
\text { (zonder LABA) }\end{array}$ & $\begin{array}{l}\text { Intermediaire tot (tijdelijk) hogere dosis } \\
\text { ICS+LABA of hogere dosis ICS (zonder LABA) } \\
\text { Overweeg stap 5 }\end{array}$ \\
\hline Bij klachten* & $\begin{array}{l}\text { Verwijzing } \\
\text { longarts } \\
\text {-bij gebruik ICS-formoterol: extra inhalatie lage dosering ICS-formoterol (maximaal 8 inh/dag)* of aanvullend SABA }\end{array}$ \\
\hline
\end{tabular}

* Gebruik >2/week wijst op onvoldoende astmacontrole. Alleen formoterol-budesonide en formoterol-beclometason zijn voor zo-nodig-gebruik geregistreerd.

Naast voorlichting, zoals prikkelvermijding, niet roken, beweging en inhalatie-instructie, is aandacht voor de medicamenteuze behandeling van belang. In dezen wordt het stappenplan in acht genomen.

\section{Nieuw medicamenteus stappenplan}

Op grond van recente publicaties zijn er aanwijzingen dat onderhoudsbehandeling met formoterol-ICS zo nodig als eerste behandelstap even goede astmacontrole geeft als ICS-onderhoudsbehandeling en in dezelfde mate longaanvallen (exacerbaties) kan voorkomen. Dit wordt gezien als een fundamentele wijziging in het astmabeleid. In deze NHG-Standaard is de nieuwe behandeloptie nu als gelijkwaardig alternatief geïntroduceerd. ICS-formoterol zo nodig is gemakkelijk implementeerbaar en de kans op overmatig SABAgebruik is vrijwel afwezig. Bij frequenter gebruik gaat men als het ware vanzelf over naar een onderhoudsdosering. Een nadeel is dat de mogelijkheid van een succesvolle onderhoudsbehandeling met laaggedoseerd ICS (zonder LABA) dan wordt overgeslagen.

\section{Zwangerschap en borstvoeding}

Een goede astmacontrole met medicamenteuze behandeling tijdens de zwangerschap is veiliger en geeft minder complicaties dan het accepteren van astmaklachten en longaanvallen door het staken van medicatie uit zorg over bijwerkingen voor het kind. Bij een ernstige longaanval weegt het voorkómen van hypoxemie zwaarder dan de eventuele risico's van systemische corticosteroïden voor de foetus en de zwangere. Een longaanval tijdens de zwangerschap wordt hetzelfde behandeld als buiten de zwangerschap.
Bij borstvoeding geldt dat formoterol en salmeterol alleen bij gebruik van een zeer hogere dosis door de moeder rusteloosheid en tachycardie bij de zuigeling kunnen veroorzaken. Over het gebruik van montelukast en tiotropium tijdens zwangerschap en borstvoeding is onvoldoende bekend. Het valt te overwegen montelukast of tiotropium (tijdelijk) te staken.

\section{Longaanval}

De term exacerbatie is vervangen door 'longaanval'. In de nieuwe NHG Behandelrichtlijn Geneesmiddelen en zuurstof in spoedeisende situatie (mei 2020) is het beleid bij een longaanval geactualiseerd. Zo is bijvoorbeeld het ademhalingsfrequentiecriterium bij een ernstige exacerbatie gewijzigd van 120 naar 100 keer per minuut. Waarden die afwijken van de normaalwaarde zijn niet altijd alarmerend en moeten op grond van de klinische bevindingen geïnterpreteerd worden; normale waarden sluiten een spoedeisend toestandsbeeld niet uit. Belangrijker is dat de er een ABCDE stabiel en instabiel onderscheid is en dat de streefwaarde voor zuurstof is vervallen.

\section{Verwijzen}

Redenen om te verwijzen zijn onder meer als er een discrepantie is tussen klachten, er longfunctie afwijkingen zijn of dat er blijvend onvoldoende astmacontrole is na 3-6 maanden. Reden voor verwijzen is ook het niet bereiken van de persoonlijke behandeldoelen ondanks stap-4-medicatie, al dan niet in combinatie met aanwijzingen voor niet-allergisch astma (onvoldoende reactie op ICS, obesitas (BMI > 30)), of als de astmaklachten op volwassen leeftijd zijn ontstaan. - 